\title{
RECENSOE S
}

AMBrozio, Leonilda. A ironia em Juan sin Tierro, de Juan Goytisolo. Rio de Janeiro, 1979. 95 p. Dissertação, Mostrado, Universidade Federal do Rio de Janeiro.

Abordando a obra culminante de um dos grandes romancistas da Espanha atual, o estudo A ironia em Juan sin Tierra, do Juan Goy. risolo, de Leonilda Ambrozo, sua dissertaçāo de Mestrado pela Universidade Federal do Rio de Janeiro, leva à realização a importante tarefa de estabelecer um aparelho teórico para o estudo da iro$\mathrm{n}$ a, recurso estilístico essencial à literatura contemporânea, onde o arisma do grotesco na visão do mundo é uma captaçāo ineludível e constante da expressão artística.

A era das. desilusões - assim poderia enquadrar-se não só o tempo desse problemático país que é a Espanha após 1936, terra de estagnação e decadência, mas o tempo de todo nosso mundo ociclental. A resposta estillistica é imediata e contundente: ironia, sátira, paródia, aspectos freqüentes sobretudo na narrativa do século $X X$, onde pode chegar-se aos extremos da autoparódia, como faz Goytisolo com sua anterior filiação ao romance comprometido com a realidade.

Como se diz no Resumo anexado, a dissertação descobre no mundo romanesco de Juan Goytisolo duas motivaçōes da ironia: o instrumento de crítica e o processo de conscientização da arte: "A ironia é a faca afiada através da qual realiza-se a ruptura com os padrões rígidos diłados pela moral castradora da sociedade espanhola. Com sua revolta, Juan sin Tierra liberta o discurso liferário de suas amarras impostas pe'a Real Academia Espanhola".

A análise penetrante e lúcida dos recursos ligados à ironia, a portir da bibliografia básica (Vladimir Jankilévich, Lausbeg, Bergson), permite à autora delimitar as diversas motivações e o desenvolvimento dos mesmos, aspecto que positivamente aparece como fundamental no corpo da tese. Assim, os capítulos 2 e 3, estudando os pressupostos teóricos da ironia e as relaçōes ironia-servidão, e ironia em oposição à sátira, à paródia e ao grotesco, três momentos que a autora define como os da repressão, totalizados de "destruição restauradora": pois a atitude irônica é superada em Goytisolo, num rojelo de criação e renovação do mundo, de esquecimento do ódio e de final redenção da Espanha. 
O trabalho de Leonilda Ambrozio poderá ser apreciado na sua originalidade se considera:mos que o estudo mais aproximado ao assunto da dissertaçāo foi publicado por Linda Gould Levine anteriormente à aparição do romance Juan sin Tierra. (Juan Goyiisolo; la destrucción creadora. México, Joaquim Mortiz, 1976. 305 p.).

$\mathrm{Na}$ linguagem clara e incisivamente didática da autora, o esiude adquire ainda sua dimensão fundamental dentro dos objetivos propostos na pós-graduação para o Mestrado: um trabalho destinado à assimilação e discussão nas salas de aula de Literatura, sempre que o objetivo for a análise dos processos da ironia e o conhecimento aprofundado da literatura espanhola mais recente.

\section{Miguelina Soifer}

DIAZ-MORENo, Ana Maria. Un estudio de Eloy, de Carlos Droguett. Poitiers, 1980. 103 p. Tesis, Maestría, Univorsiné de Poitiers.

El escritor chileno Carlos Droguet nació el 15 de octubre de 1915 en Santiago de Chile, donde cursó sus estudios literarios y ejerció durante algunos años el periodismo literario. Publica lib os desde 1940, cuando lanzó Los Asesinados del Seguro Obrero. Desconocido en su propia tierra conforme la revista Crisis n. ${ }^{\circ} 40$, de diciembre de 1973, la obra de Carlos Droguett fue tema del "Coloquio Sobre la Obra de Carlos Droguett", realizado en mayo de 1981 en el Centre de Recherches Latino-Americanes, en la Université de Poitie's, Francia, donde se reunieron los especialistas en su obra, considerada de valor universal. Acerca de su obra, está siendo preparada una edición criiico por la Editorial Cátedra, de Madrid, y también hay una serie de tesis doctorales.

En 1960 Droguett publicó su tercer libro - Eloy - traducido ya al italiano, danés, holandés, alemán y checo. Recientemente fue traducido al portugués por Cecilia Zokner. Esa novela, basada en la historia del "ñato" Eloy, bandolero perseguido y muerto por los policías en 1941, mereció un trabajo de Ana María Diaz-Mo eno: Un estudio do Eloy, de Carlos Drogueft, tesis de maestría en la Université de Poitiers, Francia, en 1980.

En ese estudio Díaz-Moreno trata de analizar la obra de Droguett bajo dos aspectos: dualidad e inversión.

En la introducción hace una síntes s muy didáctica y objetiva de Eloy. Ya en el primor ćapítulo hace un análisis del personaje: su interioridad, sus relaciones con otros personajes, con los objetos, con el 
mundo, enfín. Alcanza a analizar sus relaciones con el mundo a trovés de los niveles sensorial y emotivo. A lo largo de este capítulo. Díaz-Moreno destaca con bastante clareza el aspecto dual de la obra de Corlos Droguett. Una dualidad expresada en sentimientos con relación a sí mismo $y$ en relación con otros personajes y con los objelos que lo rodean. Tal es la dualidad de Eloy, que el personaje nos es presentado como un criminal simpático, lleno de ternura y humildad, de odio y arrogancia a la vez.

En el segundo capítulo analiza el aspecto temporal, que, como en el capítulo anterior, es un constante ir y venir. Mientras el ir y venir del primer capítulo representa una dualidad en varios niveles del personaje, en éste da idea de la agilidad y del dinamismo narrativo. Diaz-Moreno hizo el recuento de las idas y venidas temporales: 19 proyecciones hacia el futuro, 41 a recuerdos lejanos, 23 a recuerdos cercanos y 50 del momento presente. $Y$ esas digresiones y progresiones temporales"son rápidas y fundamentales en la estructura de la novela. Es en las narraciones donde más se notan las inversiones senaladas por Díaz-Moreno. Las descripciones de los entes más queridos son muy breves, sin detalles. Relata con más precisión la ciudad donde el personaje se quedó pocas horas, al paso que la ciudad donde vivió mucho tiempo, aparece apenas mencionada.

En el tercer capítulo estudia los diversos narradores de la novela, los diversos planos narrativos y el lenguaje de los narradores. $Y$ equí la autora destaca la relación de complicidad entre el lector y el personaje, a través del lenguaje utilizado por cada uno de los narradores.

En el cuarto capítulo trata de situar a Carlos Droguett dentro de la literatura y del contexto histórico-social de Chile. Analiza toda la obra de Droguett bajo ese contexto y por fín sitúa Eloy dentro de ese panorama. El análisis está muy bien estructurado, y la pesentación muy didáctica.

Por fin, en la conclusión, de forma muy objetiva, demuestra que los varios aspectos de dualidad e inversión son encontrados. en distintos niveles, estudiados anteriormente.

Formalmente, la tesis se presenta muy bien dividida, cada capitulo desarrollando integralmente lo propuesto. El lenguaje claro no deja margen a dudas, pues es siempre ilustrado con citaciones, a veces bastante extensas, pero necesarias. Observamos que las citaciones muy largas deberían ser colocadas siguiendo las normas internaciones de referencia bibliográfica. Sin embargo, aun el lector que no 
haya leído Eloy, se da cuenta de que está frente a un trabajo serio, bien estructurado, resultado de un análisis profundo de la obra de Droguett.

\section{Nair Nodoca Takeuchi}

FENGER, Henning. Kierkegaard: the myths and their origins. New Haven, Yale University Press, 1980. 234 p.

A bela ediçāo de "Kierkegaard-Myter og Kierkegaard-Kilder" vem de ser vertida para o inglês, escoimada de um excedente de caráter mais pessoal, que na verdade não apresentava nenhum interesse para o esfudioso do mestre dinamarquês, como as páginas em que Henning Fenger se refere a seus ascendentes, inteiramente prescindiveis.

A "Kierkegaardiana", de Copenhague, ainda não trouxe uma recensão dessa obra, creio porém que não pode:á ser nada favorável, embora a preocupação de Fenger não tenha sido a de destruir a ima. gem de Kierkegard como mártir, como teólogo, como dogmático e como filósofo. Na verdade, essa seria uma tarefa inglória e para a qual o autor dessa obra não me parece ter a habilitação necessária.

No entanto, Fenger traz uma contribuição inestimável do ponto ae vista da pesquisa kierkegaardiana. Não se pode negar que suas eríticas aos editores dos "Papéis" (diário) é pertinente. Mas ele poupou Earfod, o que realizou a primeira edição desses "Papéis", volfando-se irecipuamente para os preparadores da segunda edição. Suas críticas a Niels Thulstrup, editor das "Cartas", da cópia facsimilada da segunda ed çãc dos "Papéis" e autor de uma dissertação sobre Hegel e Kierkegaard, esclarecem pontos importantes da pesquisa kierkegaardina, que nós, leitores que não temos oportunidade de manusear os originais de Kierkegaard, éramos constrangidos a aceitar sem contestação. Nesse sentido Henning Fenger nos trouxe uma contr buição inestimável.

Tenho uma certa dificuldade, entretanto para aceitar a sua tese contida no primeiro capítulo de sua obra: Kie'kegaard como um falsificador da história. Se os papés, a maioria, dos primeiros anos se destinavam a uma obra, não se tratando de matéria de consciência, mas de criação, a decisão religiosa de Kierkegaard sofre um colapso em sua própria origem. Até aqui se pode asompanhar a tese de Henning Fenger.

Na verdade, porém, se o que um autor manifesta em sua obra 
pode ser um problema de ordem pessoal - e em Kierkegaard essas manifestações sempre traziam algo muito pessoal - então, tudo era concernente ao autor, principalmente quando o homem que está no fundo da obra, na condição de autor, interessa mais do que a própria obra. Isso diminui um pouco a discrepância entre o grupo de Thulstrup (Malantschuk, à parte, pois não se integrou a grupo algum)

Explico: há personagens que refletem inteiramente o autor e ourros que estão mais ou menos distantes dele. Mas, sempre e qualquer caso, os personagens são os possiveis do autor. Compreende-se a coisa dessa maneira, pouco importa - ou importa menos do que Fenger pretendeu - o fato de que as notas iniciais do "Diário" se destinassem a um livro, isto é, não dissessem respeito à problemática propriamente kierkegaardiana.

No entanto, seria abusivo uma discussão mais profunda do assun. to aqui nesła recensão, que não teve outro propósito do que chamar a atenção para um ou outro ponto do livio de Fenger.

\section{Ernani Reichmann}

GAl, Adam. Ironía y lirismo en la obra narrativa de Juan Rulfo. Jerusalem, 1980. 303 p. Tesis, Ph.D. Universidad de Jerusalem.

Nunca fue facil conceptuar. Siguiéndose los rastros de las definiciones se atraviesan siglos, mayormente viajando por meandros, muchas veces en idas $y$ venidas que semejantes o distintas, por veces, puco o nada agregan a lo que ya fue dicho. Para el investigador son, empero, viajes necesarios, obligatorios, pues solamente a partir de ellos es que puede construir su instrumento de trabajo. Adam Gai en Ironia y lirismo en la obra narrativa de Juan Rulfo, tesis para la obtención del tífulo de doctor en filosofía, presentada a la Universidad de Ierusalém, realizó ese trabajo pensando la ironía desde los clásicos hasta las teorizaciones de hoy, pasando, es evidente, por diversas manipulaciones $y$ aplicaciones que en las distintas épocas fuerom sur. giendo de los conceptos. Su propuesta de definición - la formación en mención de un verosímil, al ser este incluldo en un contexto que cuestiona su pertinencia - se basa en la hipótesis de Sperber y Wilson y se aplica a dos clases de manifestaciones: la ironía verbal y la ironía situacional. Su concepto fue aplicado a la obra narrativa de Juan Rulfo y el trabajo que realizó es la unión del aporte teórico aplieado al texto en una contribuisión que elide lo que muchas veces puede suceder: la dicotomía entre lo teórico y su aplicación practica. Constituyen el corpus del trabajo los cuentos de El llano en llamas 
Lla séptima y la décimo primera edición del Fondo de Cultu a Económica, respectivamente de 1965 e 1973. Como esclarece su autor, el uso de las dos ediciones se debe a que, a partir de 1970, las reimpresiones del libro suprimen el cuento Paso del norte y agregan EI dia del derrumbe y La herencia de Matilde Arcángel) y la novelo Podro Páramo (novena edición también del Fondo de Cultura Ecoriómica). El estudio de la ironía en esos dos tiempos tendrá por obiotivo resaltar los efectos producidos por lo que el autor denomina inscriptor o instancia inscriptora que es considerada, entonces, semánticámente relevante en los relatos de Juan Rulfo. El análisis de los cuentos, hecho independientemente, se realiza partiendo de las instancias narrativas: relatos de narración homodiegética, relatos que combinam instancia homodiegéticas y heterodiegéticas, relatos de instancia heterodiegética, relato que combina instancia heterodiegética y diblogo. La ironía es dectetada, entonces, conforme se presenta en cada cuento. Por ejemplo, en el estado de ilusión del personaje con especto a la situación que está viviendo, como oposición a los conreptos morales del lector, en uso repetitivo de un sucesso, en el comportamiento de un personaje, en ciertas antífrasis.

En Pedro Páramo la ironía en el discurso se inicia, ya, a partir de la desorientación del lector frente a la ruptura de un orden en las secuencias narrativas del texto novelesco en donde lo real, lo fantástico y lo maravilloso operam ambiguamente permitiendo cuestionar normas que son la realidad conocida del lector. La decodificación de los narradores de la novela y de esos tres niveles de verosimilitud que, normalmente, se excluyen, anteceden el estudio de la ironia de los personajes en el mundo configurado de los narradores homodiegéticos y heterodiegéticos: la ironía intencional y no intencional que emerge sea de las palabras, sea de situaciones en que se encuentran los personajes. Así, la antí-frasis de Dolores, el diálogo entre Juan Precioso y Damiana o la inconciencia de los difuntos ante su propria muerte. Para el autor es más nítida la distinción entre la ironía ejercida intencionalmente y la ironía no intencional padecida por los personajes en la narración del narrador heterodiegético. Pedro Páramo la ejerce en distintas situaciones - al mandar pedir la mano de Lola, al resolver los problemas de tierra, al provocar una orfandad, al juslificar sus crímenes y los de su hijo. De la ironía son victimas, por ejemplo, el abogado Trujillo y Renteria. Este análisis detenido de los textos llevó Adam Gai a conclusiones que resultam muy claras y aporIan a la comprensión de los textos de Rulfo elementos que, verdaderamente son importantes - la semejanza del mundo del lector al mun. do configurado por el autor implícito que aunque recree momentos 
de la vida mejicana, questiona verosímiles que en apariencia rigen ese mundo; las reticencias que caracterizam las narraciones; la mímesis de las narraciones testemoniales que llevarían al código realista si no se diluyeran en "infracciones" de la constitución de los puntos de vista y más que importantes, indiscutibles. $O$ sea, que la ironía emerja, por ejemplo, de los personajes que narran testimonialmente - el psicótico, el delincuente, el ingenuo, el difunto - pero no son (según el código establecido), capacitados para proporcionar una información digna de crédito; o del autor implícito en la asunción de rasgos orales por veces artificiosos y complejos; o del empleo insólito de determinados medios tipográficos; o la intencionalidad de los personajes dominadores para confundir a sus vívtimas; o de burla que indirectamente es hecha por los personajes dominados hacia los que los aominan; o de sifuaciones inintecionalmente irónicas sufridas por dominados y dominadores.

En la segunda parte de su trabajo, Adam Gal, asi como lo hizo también con la ironía, considera algunas de las concepciones de lirismo en su desarrollo histórico y partiendo del supuesto que es posible detectar en el discurso literario marcas distintivas del texto lírico kropone una definición de lirismo: "producto de una relación entre la figuratividad de un enunciado poético y un hablante que transformado en palavra se expresa mediante una enunciación musicalizada". Al partir de ella, hará el análisis de los cuentos y de la novela. En los cuentos, los textos líricos, considerándose la extensión de los textos narrativos, son breves. Observa Adam Gai que en algunos el lirismo se presenta como algo de episódico y que en otros, él está ausente. existe, es para descubrir sentimientos $y$ emociones que los pasajes narrativos - reticentes - descubren. Son fragmentos no miméticos, evocativos, en donde los narradores homodiegéticos y heterodiegéticos al describir el mundo configurado "suspenden provisoriamente el verosímil que rige lo narrativo". El rasgo de la irrealidad del texto lírico se obtene a través de procedimientos como el símil, la metbfora y la metonimia y el coupling (según Samuel Levin). Para el autor, en la novela Pedro Páramo, esos procedimientos ya se evidencian en la disposición gráfica. pues, además del empleo de las bastardillas, la división en capítulos se hace por medio de espacios en blanco que interrumpen la narrativa para dar al relato las zonas de silencio de la poesia. Pero, es en la actitud de los personajes que se encuentra lo Jecisivo del lirismo en la novela. El análisis se hace, entonces, a partir de los discursos del narrador heterodiegético de los discursos de Do'ores, Pedro Páramo y Susana. O sea, personajes inmersos en una soledad espacial y psiquica y en los cuales el lirismo se evidencia en 
os momentos de inacción. Las palabras líricas de Dolores tienen por objetivo la evocación de la tierra, interpretan aún el dolor y la nostalgia de quién abandonó su pueblo y su marido. El lirismo de Pedro Páramo es solamente la evocación de Susana San Juan y él de Susana, la evocación de la época de la muerte de su madre y su experiencia erótica con Florencio. La antropomorfización, los pleonasmos, los paralelismos s intácticos, las repeticiones, el coupling son los :rrocedimientos, los signos indicativos del lirismo en esos discursos.

Hay momentos del trabajo de Adam Gai que pueden ser repensados (un ejemplo: el afirmar que existe una rivalidad entre Felipa y la Madrina del cuento Macario o el encontrar conotaciones simbólicas da algunas acciones de los personajes de ese cuento). Pero es, sin duda, un trabajo en el cual no caben divagaciones y que está muy bien elaborado. Sobretodo, su originalidad consiste en ese minucioso y paciente análisis de los textos que permitió al autor llegar a conclusiones que poseen la fuerza de la argumentación bien documentada y demostrar, a par de su capacidade de investigador, una aguda sensio lidad crítica en la interpretación de los datos recogidos.

\section{Cecilia Zokner}

GARCIA MARQUEZ, Gabriel. Crónica de una muerte anunciada. Barcelona, Bruguera, 1981. 193 p.

Acabam de ser publicados no mundo hispânico dois livros de Gabriel Garcia Marques: Textos Costeños, primeiro volume de sua obra jornalistica que vem sendo compilada e Crónica de una Muerte Anunciada, livro que foi lançado como um produto de consumo, haja visto o imenso aparato publicitário que o cercou antes e no momento de sua aparição. Na verdade, com este livro Gabriel Garcia Marques quebra o silêncio que se seguiu à publicação de El Otoño del Patriarca, ou seja um silêncio de seis anos e que até agora tem sido explicado por acontecimentos extraliterários. Crónica de una Muerte Anunciada mal chega às duzentas páginas e somente admite uma leitura in nterrupta. Dizer isto, aliás, até pode causar estranhe. Zu, pois foi dito tantas vezes que já é lugar comum repetir que é um livro que se inicia desvendado o seu final: "No dia em que o iriam matar, Santiago Nasar se levantou às 5:30 da manhã $[\ldots]$ ". Nada ma's preciso, então, do que o tífu'o desta narrativa de fatos presenciados por outros que não o narrador, que apenas recompõe 27 anos depois, o que the é transmitido.

A morte anunciada no título e nas primeiras linhas da narra- 
tiva é a de Santiago Nasar. Duas horas antes que se levantasse para assistir à chegada do bispo na cidade, já era voz corrente a ameaça que pesava sobre ele. Concretizada, morreu na condição de terceiro elemento de um triângulo amoroso que ele próprio ignorava, em nome de uma honra que não foi ofendida, pelas mãos de quem verdadeiramente não desejava matar e diante de uma cidade passivamente atônita.

Na narrativa cronológica de seus passos, na explicação de cada uma das omissões e verdades se entremeiam as informaçōes sobre o assassinado (jovem, rico, religioso, caçador, mulherengo, habituado ao sangue dos bezerros que castrava e dos animais inermes que matava) e sobre os tipos que o rodeiam, figuras imutáveis que a literatura recria e torna a recriar (e Balzac e Eça) e que, de repente ou repetidamente, a vida faz existir e a sociedade atuar: o. delegado, - padre, o militar, a prostifuta, o prefeito, a criada, a mãe, a noiva. E sobre as oüras duas figuras, partes do triângulo que, digamos, existiu. São tipos que sobressaem em meio a outros quarenta. Todos èles apresentados nominalmente, alguns pela sua função na narrativa, outros pela sua função na micro-sociedade del "pueblo olvidado". Com exceção de Santiago Nasar "2l anos, esbelto e pálido, pálpebras árabes e cabelos cacheados, mão de gavião carnívoro" e de Bayardo San Román, esses tipos todos se definem por uns poucos traços, umas poucas palavras que pronunciam e principalmente por suas ações: o general Petrônio San Román usando o barco de cerimônias do congresso para ir assistir ao casamento do filho; as famílias colocando os enfermos na passagem do bispo para receber a bênção e curar-se; a exibição do lençol na manhã seguinte à noile de núpcias. Mais do que nada são a cristalização de uma socieciade tradicional onde a autoridade, as crenças, os costumes não apenấs se prestam, mas ałé exigem um traço mais forte, caricatural. E - aparecimento, na autopsia "entre o lodo do conteúdo gástrico" de uma medalha da Virgem do Carmo que Santiago Nasar havia engolido aos quatro anos ou a doença de Pedro Vicario.

O cronista não questiona. Limita-se a desejar entender a fatalidade oferecendo evocações, lembranças, numa linguagem sem sinuosidades, sem meandros, cronicamente despojada - se uma comparaç5o for feita com a sinfonia barroca do livro anterior. Porém, não suficientemente despojada a ponto de privar o texto das cen. telhas de um emprego inusitado do adjetivo, do hiperbólico, do fantástico, do eufemístico. Perfeita ao diluir o trágico que seria a inocéncia da hora e meia vivida por Santiago Nasar nesse dia e fa- 
zer emergir o còmico, o absurdo das coincidências, das explicações, Jas verdades de cada um.

Construida em idas e vindas que enovelam o leitor, é uma narrativa destinada ao sucesso de repetidas edições, embora tenha que enfrentar o paralelo inevitável com a definitiva obra-prima que é Cien Años de Soledad. Paralelo inevitável, desnecessário e inconseqüente, porque Crónica de una Muerte Anunciada não deve ser pensada como outra obra de Gabriel Garcia Marques, mas como um livro que seu autor escreveu a rir como riu Antonio Skarmeta ao escrever la Mancha ou Daniel Moyano o seu Trino del Diablo. Ao leitor de entender a hora e a vez desse riso.

\section{Cecilia Zokner}

LEITE, Luíza Baıreto e outras ef alii. O Teatro na Educação Artistica. 2..$^{\circ}$ ed. Rio de Janeiro, Achiamé, 1980.

Conheci (e utilizei) esta obra em sua primeira edição, a de 1976, quando seu título era Teatro é Cultura. Revejo-a agora em nova edição, nova capa e nova editora mas com a mesma estrutura e com - mesmo conteúdo da anterior. Trata-se de um texto de inegável valor pedagógico e cultural. Esta afirmação carece de comprovação F.ara que não permaneça apenas como uma máscara de educação aue obriga o comentador a elogiar o livro porque o recebeu em forma de cortesia da editora ou porque é amigo dos autores.

Seu valor é inegável porque todo trabalho consciente, bem intencionado e realizado com amor, voltado para a criança tem um i!:imitado valor cultural e educacional. Criança é presente e futuro. magia, imaginação, criatividade e liberdade. Trabalhar com ela é axtremamente gratificante, principalmente quando se entende tudo - que ela representa e quando se descort na toda sua capacidade de fazer, expressar e modificar.

Tudo isso senti ao ler os quatro ensaios que compōem o livro (enriquecido ainda com a peça Bom Bom no mundo do teatro):

1. "Do materna! ao pós-graduação", de Luíza Barreto Leite,

2. "Exercícios práticos", de Niette Lima,

3. "Teatro aplicado à educação", de Yara Slveira,

4. "Bonecos. sombras, criatividade e recuperação dos seres humanos", de Dudu Barreto Leite.

A tônica da obra é o fato de estar vincada na experiência pessoal das autoras e nas lições práficas que dela advieram. Fugin. 
to ao tom normativo do manual de exercícios, o livro é, antes de tudo, um depoimento.

Como fonte de reflexão (um tanto ampla mas sempre comovente e sincera) o ensaio de Luiza Barreto Leite lança-nos em di-eção ao questionamento dos porquês, quando e para quê valorizar a criança e, sobretudo, porque apresentar-the um novo canal de expressão e de realização. $O$ como colocar em prática todo este ques:ionamento fica sob a responsabilidade das três co-autoras.

Quer me parecer que tal obra (malgrado o tífulo) não se deslina exclusivamente a estudantes e professores de Educação Artística. Săo técnicas de aprendizagem e de educação alicerçadas em sólido srsenal teórico, que interessam a todos aqueles que trabalham junto à criança e com o teatro, seja no mag̣istério ou na orientação educacional, seja na psicologia ou na pedagogia.

O livro apresenta um leque bastante amplo de técnicas teatrais visando à educação integral da criança (e até mesmo do jovem e do adulto) e, o que me parece mais importante, elas funcionam como detonadoras, como ponto de partida para a formulação de novas técnicas, novos jogos dramáticos e nova força educacional.

Uma distinção importante enfatizada pelas autoras: o teatro e suas técnicas não deve ser usado como forma de transmissão de conhecimentos. Ele é sobrefudo uma forma de expressão, de criação e de revelação do mundo, equipando a criança, através do jogo, da tantasia e do desvendamento do real, para enfrentar o futuro sem medos nem traumas.

Se não bastasse o caráter objetivo da obra, só a defesa desta posição justificaria sua existência.

Outra distinção que norteia a construção do texto é a de que a "atividade dramática praticada na escola" nada tem a ver com - "teatro infantil", amador ou profissional. O que se pleiteia aqui é um Teatro na educação "que deve ser praticado por crianças". O importante é a descoberta de "como somos e porque somos em profundidade", além de propiciar uma intensa "interação grupal".

Trata-se, enfim, de uma obra que propõe uma visão otimista e criativa do espetáculo, seja ele realizado por crianças, jovens ou adultos, pois o fascínio e o poder do teatro transcendem as classificações etárias.

\section{Marta Morais da Costa}

